\title{
A Case of Precocious Puberty in a Setting with Limited Resources
}

\author{
Paudel KP, Giri S, Shrestha PS, Shrestha L, Thapa SB, Shrestha M
}

Department of Child Health

Tribhuvan University Institute of Medicine

Kathmandu Nepal.

Corresponding Author

Krishna Prasad Paudel

Kanti Childrens Hospital

Maharajgunj Kathmandu

E-mail: kp_kalyan@yahoo.com

Citation

Paudel KP, Giri S, Shrestha PS, Shrestha L, Thapa SB, Shrestha M. A Case of Precocious Puberty in a Setting with Limited Resources. Kathmandu Univ Med J 2011;36(4):315-7.

\begin{abstract}
Precocious puberty is a rare condition characterized by the development of secondary sexual characteristics before the median age for the sex. It is either gonadotropin dependent also called as central or gonadotropin independent also known as peripheral type. Hypothalamamic Hamartoma is a common cause of the central or precocious puberty due to organic brain lesion. Here we present a two year male who presented us with precocious puberty due to a hypothalamic Hamartoma.
\end{abstract}

\section{KEY WORDS}

hypothalamic hamartoma, precociuos puberty

\section{INTRODUCTION}

Precocious puberty (PP) is defined as the onset of secondary sexual characteristics before 9 years in males and before 8 years in females. ${ }^{1}$ This is due to excessive production of sex steroids which could be due to an activation of hypothalamic-pituitary-gonadal axis activation $(\mathrm{GnRH}$ dependent PP) also called as Central Precocious Puberty (CPP) or due to a nonhypothalamic mediated increase in sex steroid production (GnRH-independent PP). Out of these two types, GnRH dependent PP is the commoner one and accounts for more than $90 \%$ of girls and about $50 \%$ of boys presenting with PP. ${ }^{2}$

Hypothalamic Hamartoma $(\mathrm{HH})$ is a non-neoplastic disorganized collection of neural and glial elements at the tuber cinereum of the hypothalamus. It is a congenital malformation and is estimated to occur at the frequency of one in a million individuals. ${ }^{3}$ The common presentations of hypothalamic hamartoma include precocious puberty, gelastic or laughing epilepsy, and behavioural disorders. ${ }^{4}$

Here we present a case of a male child who presented to us with precocious puberty caused by a hypothalamic hamartoma.

\section{CASE REPORT}

A 2 year 11 months male from Dhading presented to the medical OPD of Kanti Children's hospital with complaints of presence of pubic hair since birth and rapidly growing sizes of genitalia. He was born normally after 40 weeks gestation and was the second child of unrelated healthy parents. There was no history of antenatal and postnatal problems or intake of any medications. There was no history of similar illness in the family including his five year old sister.

On examination his developmental milestones were normal in terms of his body weight and height. But his bone age was five years. Pubic hair was long, curved and dark and phallus was $8 \mathrm{~cm}$ long (non erect) with well developed glans. Testes measured $3 \mathrm{~cm} \times 1.5 \mathrm{~cm} \times 1.5 \mathrm{~cm}$. Axillary hair was absent and there was no hyperpigmentation of the skin. Sexual maturiry rating (SMR) stage 4. Further physical, neurologic and ophthalmologic examination revealed no abnormalities.

Upon investigation, his hematological and biochemical parameters were within normal limits. USG abdomen did not reveal any tumors or adrenal mass. Serum Thyroid stimlating hormone (TSH) and Follicle stimulating hormone (FSH) was within normal limits. However diurnal serum 

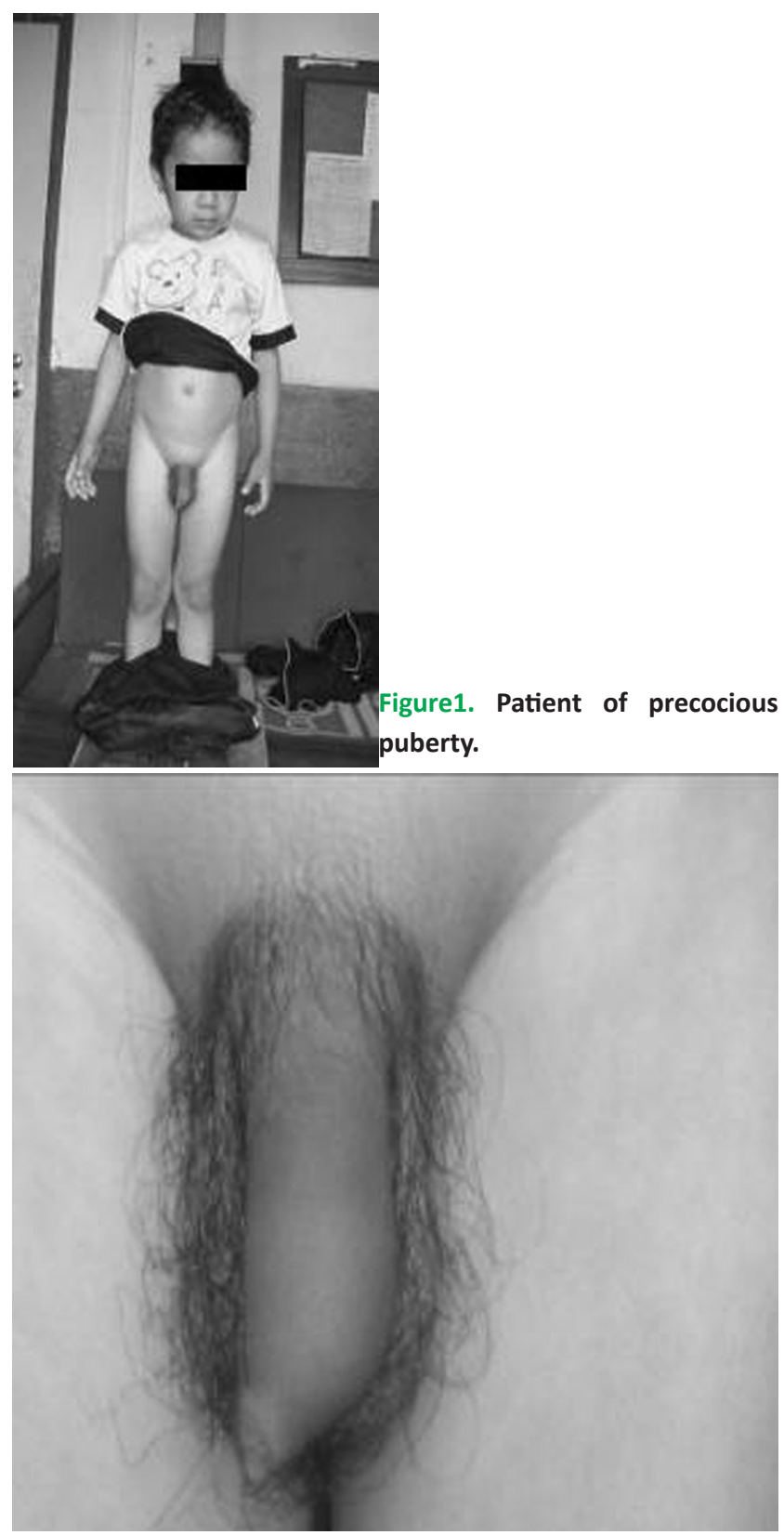

Figure 2. Genitalia of 2 yrs 11 months child (Photographs taken with permission of Grandfather).

Luteinizing hormone $(\mathrm{LH})$ was raised $(14.6 \mathrm{mU} / \mathrm{ml}$ : Normal range 1.1-8.2 $\mathrm{mU} / \mathrm{ml}$ ). Magnetic Resonance Imaging (MRI) of the brain revealed a hypothalamic mass in the suprasellar cistern, $1.2 \times 0.7 \times 0.7 \mathrm{~cm}$ in size showing an isointense signal in T1W image and hyperintense signal on T2W and FLAIR images and no enahancement on gadolinium contrast suggestive of hypothalamic hamartoma.

Based on the diagnosis of central precocious puberty due to hypothalamic hamartoma, we intitiated therapy with gonadotropin-releasing hormone analogue Leuprolide. However patient could not afford the cost of the medication and was lost to follow-up.

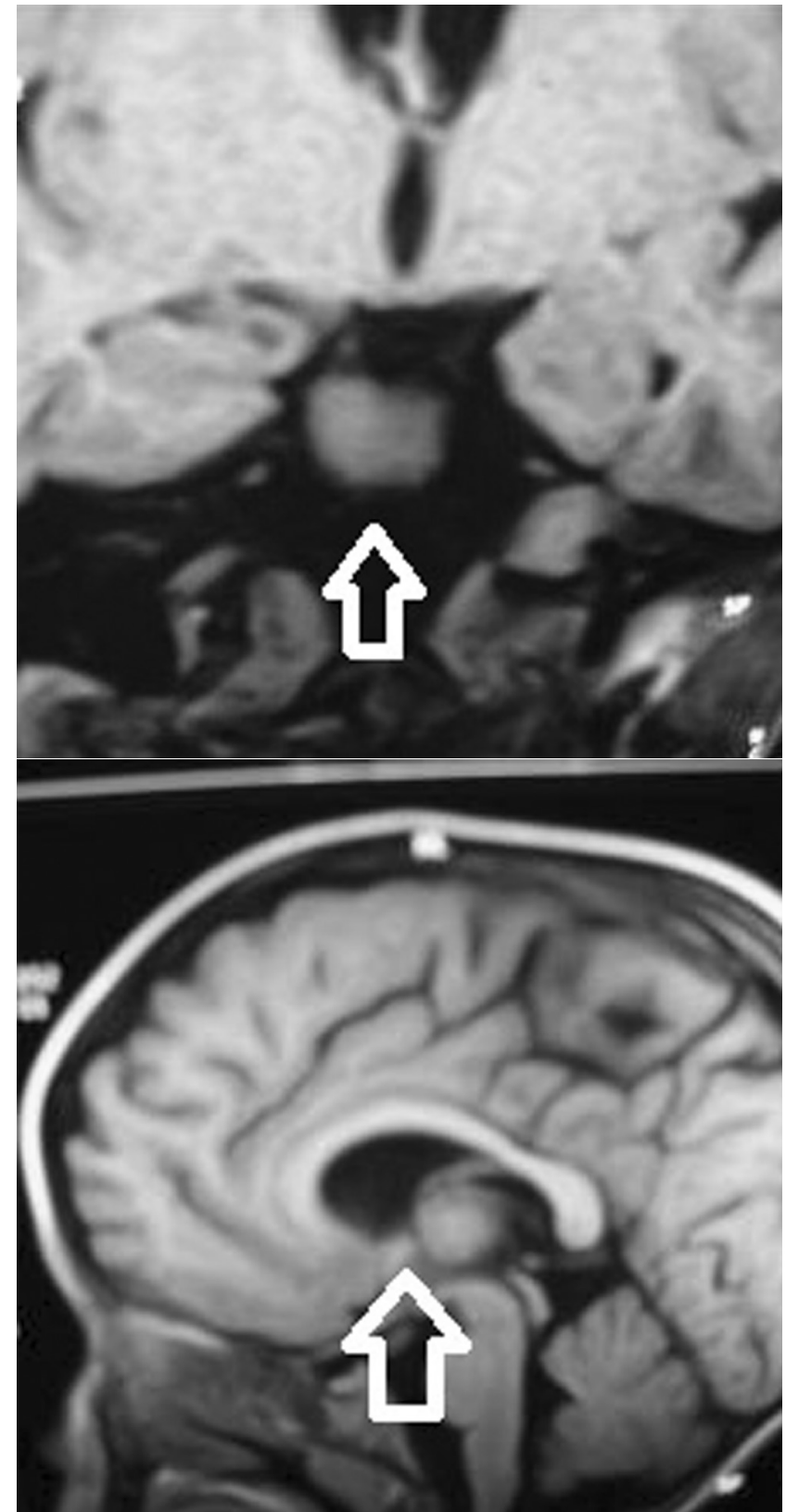

Figure 3. Midsagittal and coronal MRI of Brain showing hypothalamic hamartoma.

\section{DISCUSSION}

Precocious puberty is an unusually early onset of puberty, statistically defined as -2.5 to 3.0 SDs below the average age of onset of puberty in healthy children5. It is a relatively rare condition. A Danish population study showed an incidence of 20 per 10,000 in girls and less than five per 10,000 in boys.

The Gonadotrophin dependent type (GDPP) also known as central precocious puberty is the most common subtype and is characterized by an early maturation of the hypothalamic-pituitary-gonadal axis. This is much more common in girls than boys. Here the pattern and timing of pubertal events progresses in the normal sequence. ${ }^{6}$ Eighty to ninety percent of GDPP will have no identifiable cause (idiopathic GDPP) and this condition will have a 
striking female predominance. ${ }^{6,7}$ The other important causes include CNS tumors, trauma, infections, primary hypothyroidism, hydrocephalus, cysts etc. ${ }^{6}$

Hypothalamic Hamartoma is a relatively rare congenital malformation usually associated with central precocious puberty and gelastic seizures. This tumor is composed of redundant brain tissue with a haphazard assembly of neurons, nerve fibers, and neuroglial cells in inappropriate distributions and proportions. ${ }^{7}$ The association of hypothalamic hamartoma with precocious puberty has long be recognized. In fact hypothalamic hamartoma is one of the most common cerebral lesions associated with precocious puberty. ${ }^{8}$

Children with precocious puberty due to hypothalamic hamartomas usually present before four years of age. ${ }^{9}$ Although the mechanism for precocious puberty is not known, the prevailing view is that hypothalamichamartomas contain ectopic Luteinizing Hormone Releasing Hormone (LHRH) neurosecretory neurons which are unrestrained by the normal negative feedback mechanisms and produce secretory bursts of LHRH. ${ }^{10}$

Our patient had a normal pattern of pubertal growth, a quicker skeletal maturity, and an elevated level of Luteinizing hormone (LH). All these findings are characteristic of GDPP or central precocious puberty..$^{10} \mathrm{MRI}$ is the primary imaging modality for detection of Hypothalamic Hamartomas allowing better tissue characterization and greater anatomic details. ${ }^{11}$ The imaging features most commonly consist of a hypothalamic mass isointense to grey matter on T1W sequence, and increased signal intensity on T2W and FLAIR (fluid attenuated inversion Recovery) sequence. ${ }^{7}$ The MRI of our patient revealed all of these features.

Medical treatment with long-acting $\mathrm{GnRH}$ agonists is the first choice of treatment in patients with CPP due to Hypothalamic Hamartoma. ${ }^{12}$ In particular, depot preparations ensure an adult height within the genetic height potential with normal body proportions, bone density and reproductive function. ${ }^{13}$ Surgical resection of the hypothalamic hamartoma is indicated only in cases of progressive neurological deficit, hydrocephalus, and progressive enlargement of the mass and intractable seizures. ${ }^{14}$

\section{REFERENCES}

1. Boepple, PA, Crowley, WF Jr. Precocious puberty. In: Adashi, EY, Rock, JA, Rosenwaks, editors. Reproductive Endocrinology, Surgery, and Technology. Philadelphia: Lippincott-Raven; 1996. p. 989

2. Lee PA, Houk CP. Puberty and Its Disorders. In: Lifshitz F, editor. Pediatric Endocrinology. New York: Informa Healthcare; 2007.p. 273-303.

3. Arita K, Ikawa F, Kurisu K, et al. The relationship between magnetic resonance imaging findings and clinical manifestations of hypothalamic hamartoma. J Neurosurg 1999;91:212-20

4. Tturm JW, Andermann F, Berkovic SF. "Pressure to laugh": an unusual epileptic symptom associated with small hypothalamic hamartomas. Neurology 2000;54:971-973.

5. Sun, SS, Schubert, CM, Chumlea, WC, et al. National estimates of the timing of sexual maturation and racial differences among US children. Pediatrics 2002;110:911.

6. Chemaitilly, W, Trivin, C, Adan, L, et al. Central precocious puberty: clinical and laboratory features. Clin Endocrinol 2001;54:289.

7. Shaheen F, Hakim A, Wani M, Asmi R. Hypothalamic hamartoma presenting with gelastic seizures and precocious puberty: report of a case. Eastern Journal of Medicine 2010;15:67-70.

8. Hahn FJ, Leibrock LG, Huseman CA, Makos MM. The MR appearance of hypothalamic hamartoma. Neuroradiology 1988;30:65-68.

9. Cassio A, Cacciari E, Zucchini S, Balsamo A, Diegoli M, Orsini F. Central precocious puberty: clinical and imaging aspects. J Pediatr Endocr Metab 2000;13:703-708

10. Rousso IH, Kourti MR, Panpandrecu DR, Tragiannidis AR, Athanasiadou FR. Central precocious puberty due to hypothalamic hamartoma in a 7 month-old infant girl. Eur J Pediatr 2008;167:583-585.

11. Karnaze MG, Sartor K, Winthrop JD, Gado MH, Hodges FJ. 3rd. Suprasellar lesions: evaluation with MR imaging. Radiology 1986;161:77-82.

12. Feuillan PP, Jones JV, Barnes K, Oerter-Klein K, Cutler GB. Reproductive axis after discontinuation of gonadotropin releasing hormone analogue treatment of girls with precocious puberty: long term follow-up comparing girls with hypothalamic hamartoma to those with idiopathic precocious puberty. J Clin Endocr Metab 1999;84:4449.

13. Heger S, Partsch CJ, Sippell WG (1999) Long-term outcome after depot gonadotropin-releasing hormone agonist treatment of central precocious puberty: final height, body proportions, body composition, bone mineral density, and reproductive function. J Clin Endocr Metab 1999;84:4583-4590.

14. de Brito VN, Latronico AC, Arnhold IJ, Lo LS. Domenice S. Treatment of gonadotrophin dependent precocious puberty due to hypothalamic hamartoma with gonadotrophin releasing harmone agonist depot. Arch Dis Child 1999;80:231-234. 